\section{$429-T-4$}

t
E 1.28: ANL-79-89

ANL-79-89

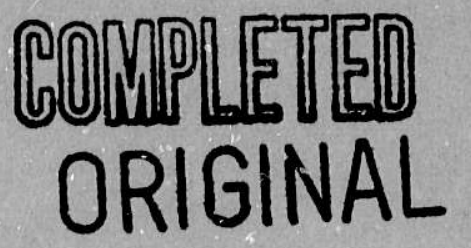

\title{
A QUASI-EULERIAN METHOD FOR ANALYZING SLUG IMPACT AND COOLANT SPILLAGE IN A FAST-REACTOR ACCIDENT
}

by

Han Y. Chu

BASE TECHNOLOGY

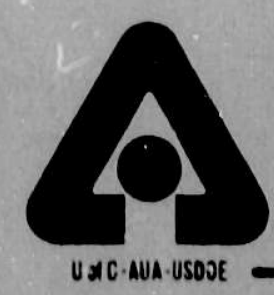

ARGONNE NATIONAL LABORATORY, ARGONNE, ILLINOIS

Prepared for the U. S. DEPARTMENT OF ENERGY under Contract W-31-109-Eng-38 
The facilities of Argonne National Laboratory are owned by the United States Government. Under the terms of a contract (W-31-109-Eng-38) among the U. S. Department of Energy, Argonne Universities Association and The University of Chicago, the University employs the staff and operates the Laboratory in accordance with policies and programs formulated, approved and reviewed by the Association.

\title{
MEMBERS OF ARGONNE UNIVERSITIES ASSOCIATION
}

The University of Arizona

Carnegie-Mellon University

Case Western Reserve University

The University of Chicago

University of Cincinnati

Illinois Institute of Technology

University of Illinois

Indiana University

The University of Iowa

Iowa State University
The University of Kansas

Kansas State University

Loyola University of Chicago

Marquette University

The University of Michigan

Michigan State University

University of Minnesota

University of Missouri

Northwestern University

University of Notre Dame
The Ohio State University

Ohio University

The Pennsylvania State University

Purdue University

Saint Louis University

Southern Illinois University

The University of Texas at Austin

Washington University

Wayne State Universiiy

The University of Wisconsin-Madison

\begin{abstract}
NOTICE
This report was prepared as an account of work sponsored by an agency of the United States Government. Neither the United States Government or any agency thereof, nor any of their employees, make any warranty, express or implied, or assume any legal liability or responsibility for the accuracy, completeness, or usefulness of any information, apparatus, product, or process disclosed, or represent that its use would not infringe privately owned rights. Reference herein to any specific commercial product, process, or service by trade name, mark, manufacturer, or otherwise, does not necessarily constitute or imply its endorsement, recommendation, or favoring by the United States Government or any agency thereof. The views and opinions of authors expressed herein do not necessarily state or reflect those of the United States Government or any agency thereof.
\end{abstract}

Printed in the United States of America Available from

National Technical Information Service

U. S. Department of Commerce

5285 Port Royal Road

Springfield, VA 22161

NTIS price codes

Printed copy: $\mathrm{A} 03$

Microfiche copy: A01 
Distribution Category:

LMFBR - -Safety (UC-79p)

ANL-79-89

\section{ARGONNE NATIONAL LABORATORY}

9700 South Cass Avenue

Argonne, Illinois 60439

A QUASI-EULERIAN METHOD FOR

ANALYZING SLUG IMPACT AND COOLANT SPILLAGE

IN A FAST-REACTOR ACCIDENT

by

Han Y. Chu

Reactor Analysis and Safety Division

December 1979 



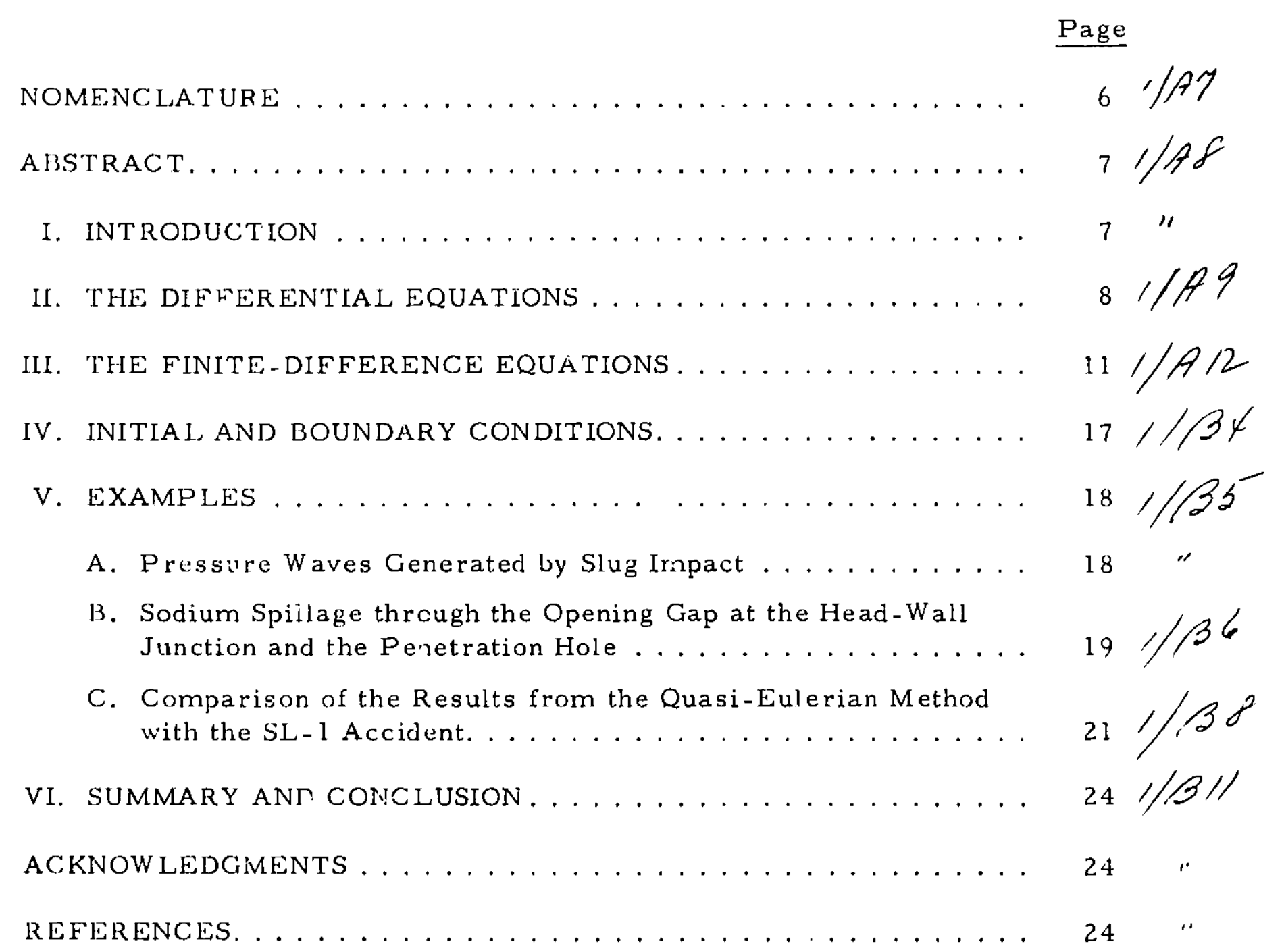




\section{LIST OF FIGURES}

No.

Title

Page

1. Quasi-Eulerian Cells and Penetration Holes. . . . . . . . . .

$9.1 / 2,10$

2. Control Volume for Momentum Equation . . . . . . . . . . 10 10

3. Control Volume for Momentum Equation on Top Side of the Uppermost Regular Cell . . . . . . . . . . . . . . . 11:1/2

4. Velocities in the Boundary Cell above the Quasi-Eulerian Cell . . $17: 34$

5. Theoretical Slug-impact Model ............... 18/30

6. Water-hammer Impulse for Theoretical Slug-impact Model . . . 19"36

7. Effect of Flexible Wall upon Pressure Unloading. . . . . . . . . . 19

8. Initial Reactor Configuration for Example B. . . . . . . . $20 \% / 2$ ?

9. Mechanical Properties of Vessel Wall. . . . . . . . . . . . 20

10. Reactor Configurations at Various Times ............. 20.

11. Plug-force Histories ......................... $21 /$ js

12. Slug-impact Model for SL-1 .......................34

13. Vessel Deformation of Deformed SL-1 Profile......... $23 / 3 心$ 
NOMENCLATURE

\begin{tabular}{|c|c|}
\hline c & Sonic velocity \\
\hline $\mathrm{d} \%$ & $\begin{array}{l}\text { Axial size of the quasi- } \\
\text { Eulerian cell }\end{array}$ \\
\hline $\bar{g}$ & Body-acceleration vector \\
\hline$g_{r}$ & $\begin{array}{l}\text { Body acceleration in } \\
r \text { direction }\end{array}$ \\
\hline$g_{\%}$ & $\begin{array}{l}\text { Body acceleration in } \\
z \text { direction }\end{array}$ \\
\hline $\mathrm{i}$ & $\begin{array}{l}\text { Subscript counting zrnes } \\
\text { from left to right }\end{array}$ \\
\hline j & $\begin{array}{l}\text { Subscript counting zones } \\
\text { from bottom to top }\end{array}$ \\
\hline P & $\begin{array}{l}\text { Superscript indicating } \\
\text { iteration cycle }\end{array}$ \\
\hline $\mathrm{n}$ & $\begin{array}{l}\text { Superscript for beginning- } \\
\text { of-cycle quantity }\end{array}$ \\
\hline$n+1$ & $\begin{array}{l}\text { Superscript for advanced- } \\
\text { time quantity }\end{array}$ \\
\hline $\bar{n}$ & Outward normal of surface $S$ \\
\hline $\mathrm{P}$ & $\begin{array}{l}\text { Sum of scalar pressure and } \\
\text { viscous stresses }\end{array}$ \\
\hline $\mathrm{p}$ & Scalar pressure \\
\hline$\overline{\mathrm{p}}$ & Iterated pressure \\
\hline$P_{0}$ & Pressure outside containment \\
\hline 9 & Artificial viscous pressure \\
\hline $\mathbf{r}$ & $\begin{array}{l}\text { Coordinate in the radial } \\
\text { direction }\end{array}$ \\
\hline$S$ & Surface \\
\hline $\mathrm{t}$ & Time: \\
\hline$\overline{\mathrm{u}}$ & Velocity Vector \\
\hline
\end{tabular}

u Velocity component in

$r$ direction

$\mathrm{V} \quad$ Volume

$v \quad$ Velocity component in

$z$ direction

$\vec{v} \quad$ Iterated cover -heat velocity

$v_{o} \quad$ Velocity at the penetration hole

$z$ Coordinate in the axial direction

$\beta \quad$ Heat-conduction coefficient

$\delta \mathrm{r}$ Radial size of the regular and quasi-Eulerian cell

st Time increment

$\delta z$ Axial size of the regular cell

$\epsilon \quad$ Small number of order $10^{-4}$

1. Area ratio (penetration hole/ cell area on top)

$\theta \quad$ Time-weighting constant for mass equation

$\lambda \quad$ First viscosity coefficient

$\mu \quad$ Second viscosity coefficient

$\S$ Constant used for donor-cell difference form

p Density

Po Density of the fluid outside containment

$\varphi \quad$ Time-weighting constant for momentum equation 


\title{
A QUASI-EULERIAN METHOD FOR \\ ANALYZING SLUG IMPACT AND COOLANT SPILIAAGE \\ IN A FAST-REACTOR ACCIDENT
}

by

Han Y. Chu

\begin{abstract}
This report describes a quasi-Eulerian method which has been incorporated into the ICECO code to study slug impact and coolant spillage problems in a fast-reactor accident. The quasi-Eulerian cells used in this method are located on the tops of the regular cells. The axial size of the quasiEulerian cells varies according to the gap generated at the reactor hedu-wall junction. Penetration holes on the cover head are modeled on the top center of the quasi-Eulerian cells. Fluid variables in these quasi-Eulerian cells also satisfy all the conservation equations. Since the boundary pressures above the quasi-Eulerian cells are determined by the movement of the moving grid, the velocity of the rover head is also included in the pressure iteration. Several examples are given to compare the results obtained by this quasi-Eulerian method with the existing experimental excursion data, as well as with the analytical and the other code solutions.
\end{abstract}

\section{INTRODUCTION}

The slug impact ${ }^{1}$ is a major concern in the reactor safety analysis. In a hypothetical core-disruptive accident (HCDA), core encrgy is transmitted to the adjacent media first by pressure waves, and then by continuous core expansions. As a result, significant movement of the coolant is encountered in the upward axial direction. When the coolant slug comes into sudden contact with the reactor cover, the cover may lift, the penetrations may open, and the upper vessel wall may deform plastically. The seal may rupture and cause coolant to spill into the secondary containment.

Although Eulerian hydrodynamics ${ }^{2,3}$ is ideal for long-rluration calculations for prohlems involving large material distortions and in-flow and outflow boundary conditions, the Eulerian grids in the numerical calculations are fixed in space. They do not vary with time. This is different from the gap generated by the slug-impact force on the reactor cover where the size of the opening varies with the displacement. In addition, the in-flow and out-flow 
openings are limited to multiples of the grid size. For small penetration holes, the Eulerian-grid size must also be made small accordingly. This results in a large number of Eulerian meshes and large computer memory storage. To overcome these limitations, this report deals with a quasiEulerian method that allows (1) the axial size of the Eulerian cells to inc: ease as the head moves upward, and (2) the use of larger Eulerian-grid size other than that of the penetration hole.

In the quasi-Eulerian method, a row of quasi-Eulerian cells, whose sizes vary in the axial direction according to the head displacement, is introduced on the tops of the regular cells. Based on an area ratio, the penetration holes a re modeled at the top center of the quasi-Eulerian celìs. The fluid variables in the regular and quasi-Eulerian cells are solved by the ICE technique. ${ }^{3}$ Since solutions for the regular cells have been described in detail in the ICECO code, ${ }^{2}$ emphasis in this refort is therefore concentrated on the numerical solutions for the quasi-Eulerian cells.

In Sec. III, mathematical formulations and numerical sclutions of the quasi-Eulerian cells are described in detail. Initial and boundary conditions are given in Sec. IV. The quasi-Eulerian method is validated in Sec. V, which compares the quasi-Eulerian-method predicted results with the analytical and the other code solutions, as well as with existing experimental excursion data.

\section{THE DIFFERENTIAL EQUATIONS}

The Eulerian hydrodynamics differential equations to be solved are

$$
\begin{aligned}
& \frac{\partial \rho}{\partial t}+\nabla \cdot \rho \bar{u}=0, \\
& \frac{\partial \rho \bar{u}}{\partial t}+\nabla \cdot \rho \bar{u} \bar{u}=-\nabla p+\rho \bar{g},
\end{aligned}
$$

and

$$
\frac{\partial \rho E}{\partial t}+\nabla \cdot \rho E \bar{u}-\mu \beta \nabla^{2} I=-\nabla \cdot \mu \bar{u}+\rho \bar{g} \cdot \bar{u},
$$

in which $E=I+\frac{1}{2} \bar{u} \cdot \vec{u}, I$ is the specific internal energy, $D$ is the density, $\bar{u}$ is the velocity, and $\bar{g}$ is the body acceleration. The heat-conduction term has been changed by introducing the coefficient $\beta$ related with the $I$, and the term $p$ includes both the scalar pressure, which is a function of $p$ and $I$, and the viscous stresses.

For problems involving shock waves, an artificial dissipative term, $q$, is added to the scalar pressure to smear out the discontinuity calculation. A 
suitable expression for $q$, which is linear in the velocity divergence, is

and

$$
\mathrm{q}=-(\lambda+2 \mu) \nabla \cdot \overline{\mathrm{u}}, \text { if } \nabla \cdot \overrightarrow{\mathrm{u}}<0,
$$

$$
q=0, \text { if } \nabla \cdot \bar{u} \geq 0 \text {, }
$$

in which the viscosity coefficients $\lambda$ and $\mu$ have been chosen to be constants. Viscous-stress terms are given in details in Ref. 2; in this report, these complications are omitted to simplify the presentation of the quasi-Eulerian method.

The conservations of mass, momentum, and energy are easily related to the computational grids by integrating those equations over a volume element, $V$. If we denote the surface of $V$ by $S$ and neglect the heat-conduction term in the transient study, Eqs. 1-3 become

$$
\begin{aligned}
& \frac{d}{d t} \int_{V} \rho d V+\int_{S} \rho \bar{u} \cdot \bar{n} d S=0, \\
& \frac{d}{d t} \int_{V} \rho \bar{u} d V+\int_{S} \rho \bar{u} \bar{u} \cdot \bar{n} d S+\int_{V} \nabla P d V-\int_{V} \rho \bar{g} d V=0,
\end{aligned}
$$

and

$$
\frac{d}{d t} \int_{V} \rho E d V+\int_{S} \rho E \bar{u} \cdot \bar{n} d S+\int_{S} P \bar{u} \cdot \bar{n} d S-\int_{V} \rho \bar{g} \cdot \bar{u} d V=0 .
$$

in which $\bar{n}$ is the outward normal of the surface $S$.

The finite-difference equations presented in the following section are wr tten as approximations to these integral equations based on two-dimensional cylindrical coordinates $(r, z)$ with azimuthal symmetry. In Eqs. 5 and $7, V$ is the volume of a mesh cell [regular or quasi-Eulerian cell (see Fig. 1)]; in

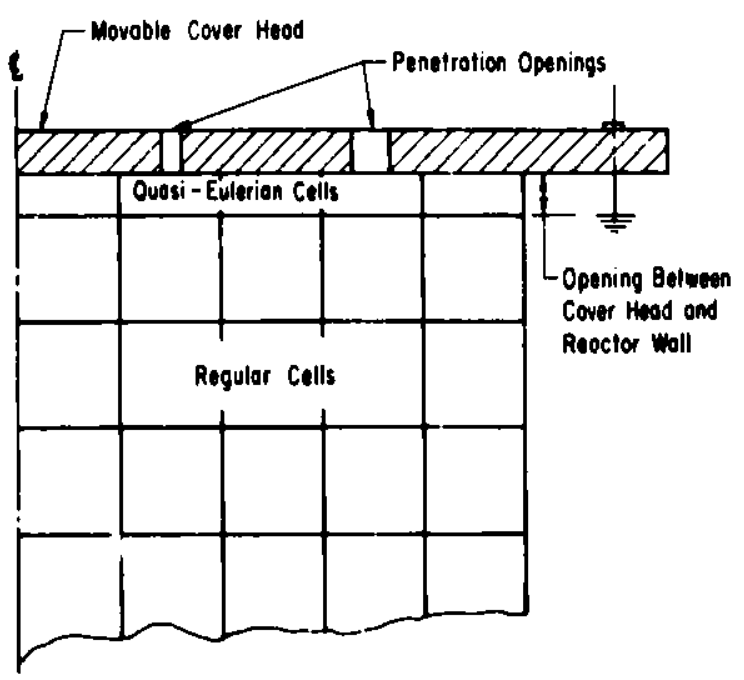

Fig. 1

Quasi-Eulerian Cells and Penetraticn Holes. ANL Neg. No. 900-5776 Rev. 
Eq. 6, $\mathrm{V}$ is a volume surrourding one of the cell sides, as shown in Fig. 2 . This difference in integration volumes is dictated by having defined densities and energies at cell centers, while velocities are defined at the centers of the cell sides.

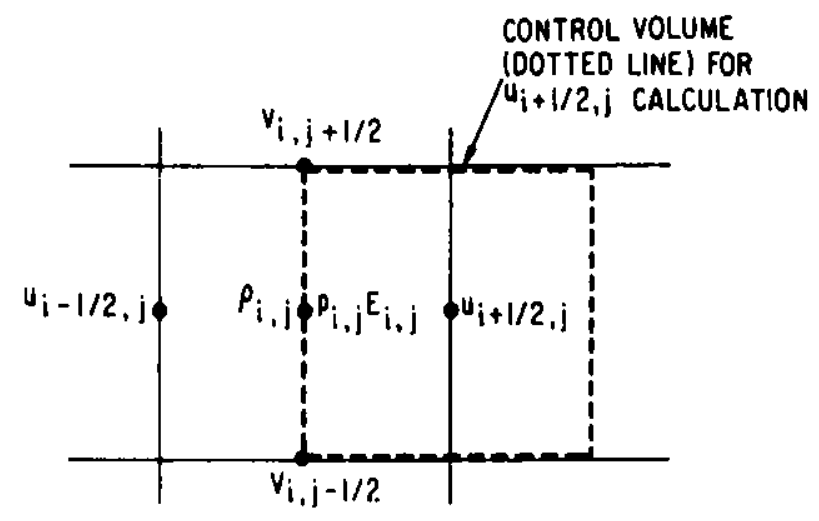

Fig. 2

Control Volume for Momentum Equation 


\section{THE FINITE-DIFFERENCE EQUATIONS}

For slug-impact and sodium-spillage studies, only one row of the quasi-Eulerian cells is needed on the top of the regular cells to simulate the cover-head motion (see Fig. 1). The axial size of the quasi-Eulerian cells changes according to the opening gap generated at the reactor head-wall junction. Penetration holes on the reactor cover head are considered to be located at the top centers of the quasi-Eulerian cells (see Fig. l).

During impact, fluid variables change abruptly from one cell to another cell. A donor-cell difference form, which assists in giving an automatic mitigation of truncation-error effects without the necessity for an explicit artificial diffusion, is used for the convective terms in the numerical calculation. Quantities inside the angular bracket in this report are those donor-cell convective fluxes. For example, a typical quantity, $Q$, expressed in the donor-cell difference form, is

$$
\langle Q u\rangle_{i+(1 / 2), j}=u_{i+(1 / 2), j}\left[\left(\frac{1}{2}+\xi_{i+(1 / 2), j}\right) Q_{i, j}+\left(\frac{1}{2}-\xi_{i+(1 / 2), j}\right) Q_{i+1, j}\right] \text {, }
$$

where $\xi_{i+(1 / 2), j}=0.5 \operatorname{SIGN}\left(u_{i+(1 / 2), j}\right)$ represents a complete donor-cell treatment.

The finite-difference approximation for the regular cells is the same as described in the Implicit Continuous - fluid Eulerian (ICE) technique ${ }^{3}$, except for those uppermost regular cells adjacent to the quasi-Eulerian cells. For those regular cells, the control volumes on the top side for momentum evaluation are adjusted by the axial size of the quasi-Eulerian cells, as shown in Fig. 3. The finite-difference formulation of the quasi-Eulerian cells with the moving grid and with penetration holes on the top is new and requires rederivation.

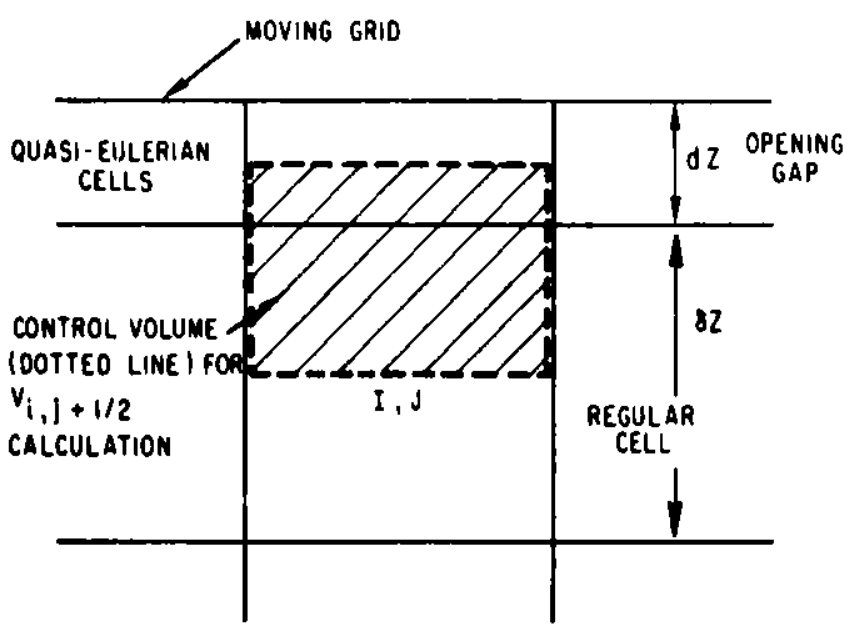

Fig. 3

Control Volume for Momentum Equation on Top side of the Uppermost Regular Cell 
For the finite-difference forms of the momentum equations of the quasi-Eulerian cells, it is convenient to separate those parts that do not contain the advanced-time factors. Thus, one defines

$$
\begin{aligned}
& A_{i-(1 / 2), j}=\frac{1}{r_{i-(1 / 2) \delta r}}\left(r_{i-1}\left\langle\rho u^{2}\right\rangle_{i-1, j}-r_{i}\left\langle\rho u^{2}\right\rangle_{i, j}\right)+\frac{1}{d z}\left\{\langle\rho u v\rangle_{i-(1 ; 2), j-(1 / 2)}\right. \\
& -\frac{\eta_{i-1}\left(r_{i-1}+\frac{\eta_{i-1}}{4} \delta r\right)}{2 r_{i-(1 / 2)}}\left\langle\rho u v_{0}\right\rangle_{i-1, j+(1 / 2)}-\frac{\eta_{i}\left(r_{i}-\frac{\eta_{i}}{4} \delta r\right)}{2 r_{i-(1 / 2)}}\left\langle\rho u v_{0}\right\rangle_{i, j+(1 / 2)} \\
& \left.-\left[1-\frac{\eta_{i-1}\left(r_{i-1}+\frac{\eta_{i-1}}{4} \delta r\right)+\eta_{i}\left(r_{i}-\frac{\eta_{i}}{4} \delta r\right)}{2 r_{i-(1 / 2)}}\right]\langle\rho u v\rangle_{i-(1 / 2), j+(1 / 2)}\right\} \\
& +\frac{1}{\delta r}\left(q_{i-1, j}-q_{i, j}\right)+g_{r} \rho_{i-(1 / 2), j}, \\
& B_{i+(1 / 2), j}=\frac{1}{r_{i+(1 / 2)^{\delta r}}}\left(r_{i}\left\langle f u^{2}\right\rangle_{i, j}-r_{i+1}\left\langle\rho u^{2}\right\rangle_{i+1, j}\right)+\frac{1}{d z}\left\{\langle\rho u v\rangle_{i+(1 / 2), j-(1 / 2)}\right. \\
& -\frac{\eta_{i}\left(r_{i}+\frac{\eta_{i}}{4} \delta r\right)}{2 r_{i+(1 / 2)}}\left\langle\rho u v_{0}\right\rangle_{i, j+(1 / 2)}-\frac{\eta_{i+1}\left(r_{i+1}-\frac{\eta_{i+1}}{4} \delta r\right)}{2 r_{i+(1 / 2)}}\left\langle\rho u v_{0}\right\rangle_{i+1, j+(1 / 2)} \\
& \left.-\left[1-\frac{\eta_{i}\left(r_{i}+\frac{\eta_{i}}{4} \delta r\right)+\eta_{i+1}\left(r_{i+1}-\frac{\eta_{i+1}}{4} \delta r\right)}{2 r_{i+(1 / 2)}}\right]\langle\rho u v\rangle_{i+(1 / 2), j+(1 / 2)}\right\} \\
& +\frac{1}{\delta r}\left(q_{i, j}-q_{i+1, j}\right)+g_{r} \rho_{i}+(1 / 2), j, \\
& C_{i, j-(1 / 2)}=\frac{2}{d z+\delta z}\left(\left\langle\rho v^{2}\right\rangle_{i, j-1}-\left\langle\rho v^{2}\right\rangle_{i, j}\right)+\frac{1}{r_{i} \delta r}\left[r_{i-(1 / 2)}\langle\rho u v\rangle_{i-(1 / 2), j-(1 / 2)}\right. \\
& \left.-r_{i+(1 / 2)}\langle\rho u v\rangle_{i+(1 / 2), j-(1 / 2)}\right]+\frac{2}{d z+\delta z}\left(q_{i, j-1}-q_{i, j}\right)+f_{i, j-(1 / 2)} g_{z},
\end{aligned}
$$


and

$$
\begin{aligned}
D_{i, j+(1 / 2)}= & \frac{\eta_{i}}{d z}\left(\left\langle\rho v_{0}^{2}\right\rangle_{i, j}-\left\langle\rho v_{0}^{2}\right\rangle_{i, j+1}\right)+\frac{1-\eta_{i}}{d z}\left(\left\langle\rho v^{2}\right\rangle_{i, j}-\left\langle\rho v^{2}\right\rangle_{i, j+1}\right) \\
& +\frac{1}{r_{i} \delta r}\left[r_{i-(1 / 2)}\langle\rho u v\rangle_{i-(1 / 2), j+(1 / 2)}-r_{i+(1 / 2)}\langle\rho u v\rangle_{i+(1 / 2), j+(1 / 2)}\right] \\
& +\frac{1}{d z}\left(q_{i, j}-q_{i, j+1}\right)+\eta_{i} \frac{\rho_{o_{i, j+1}}+\rho_{i, j}}{2} g_{z}+\left(l-\eta_{i}\right) \frac{\rho_{i, j+1}+\rho_{i, j}}{2} g_{z},
\end{aligned}
$$

in which $\eta_{i}$ is the ratio of the penetration opening area to the cell area on top, $v_{O}$ is the velocity at the penetration hole, $f_{O}$ is the density outside the containment, $d z$ and $6 z$ are axial sizes of the quasi-Eulerian and regular cells, respectively, $u$ and $v$ are the components of the velocity in the radial and axial directions, respectively.

When values of the fluid variables are required at localilies other than their point of definition, a simple average is generally used. The only exceptions to this rule are those terms expressing momentum transport normal to the calculated direction. In such cases, the monientum flux is taken in the direction indicated by the flow field. The term $\langle\rho u v\rangle_{i-(1 / 2), j-(1 / 2)}$ in Eq. 9, for example, expressing the flux of $r$-direction momentum in the $z$ direction could assume either of the two possible forms:

$\langle\rho u v\rangle_{i-(1 / 2), j-(1 / 2)}=\left\{\begin{array}{l}\frac{v_{i-1, j-(1 / 2)}+v_{i, j-(1 / 2)}}{2} \frac{p_{i-1, j-1}+p_{i, j-1}}{2}\left(u_{i-(1 / 2), j-1}\right), \text { if } \frac{v_{i-1, j-(1 / 2)}+v_{i, j-(1 / 2)}}{2}>0 \\ \frac{v_{i-1, j-(1 / 2)}+v_{i, j-(1 / 2)}}{2}-\frac{p_{i-1, j}+p_{i, j}}{2}\left(u_{i-(1 / 2), j}\right), \text { if } \frac{v_{i-1, j-(1 / 2)}+v_{i, j-(1 / 2)}}{2} \leq 0 .\end{array}\right.$

A similar prescription applies to the other flux terms.

With these defined quantities, the finite-difference forms of the momentum equations can be written

$$
\begin{aligned}
& \frac{\langle\rho u\rangle_{i-(1 / 2), j}^{n+1}-\langle\rho u\rangle_{i-(1 / 2), j}^{n}}{\delta t}= \frac{\varphi}{\delta r}\left(\bar{P}_{i-1, j}-\bar{P}_{i, j}\right) \\
&+\frac{1-\varphi}{\delta r}\left(P_{i-1, j}^{n}-P_{i, j}^{n}\right)+A_{i-(1 / 2), j}, \\
& \frac{\langle\rho u\rangle_{i+(1 / 2), j}^{n+1}-\langle\rho u\rangle_{i+(1 / 2), j}^{n}}{\delta t} \frac{\varphi}{\delta r}\left(\bar{P}_{i, j}-\bar{P}_{i+1, j}\right) \\
&+\frac{1-\varphi}{\delta r}\left(P_{i, j}^{n}-P_{i+1, j}^{n}\right)+B_{i+(1 / 2), j} \cdot
\end{aligned}
$$




$$
\begin{aligned}
\frac{\langle\rho v\rangle_{i, j-(1 / 2)}^{n+1}-\langle\rho v\rangle_{i, j-(1 / 2)}^{n}}{\delta t} & =\frac{2 \varphi}{d z+\delta z}\left(\bar{P}_{i, j-1}-\bar{P}_{i, j}\right) \\
& +\frac{2(1-\varphi)}{d z+\delta z}\left(P_{i, j-1}^{n}-P_{i, j}^{n}\right)+C_{i, j-(1 / 2)},
\end{aligned}
$$

and

$$
\begin{aligned}
& \eta_{i} \frac{\left\langle\rho v_{0}\right\rangle_{i, j+(1 / 2)}^{n+1}-\left\langle\rho v_{0}\right\rangle_{i, j+(1 / 2)}^{n}}{\delta t}+\left(1-\eta_{i}\right) \frac{\langle\rho v\rangle_{i, j+(1 / 2)}^{n+1}-\langle\rho v\rangle_{i, j+(1 / 2)}^{n}}{\delta t} \\
& \quad=\frac{\eta_{i}}{d z}\left[\varphi\left(\bar{P}_{i, j}-\bar{P}_{o_{i, j+1}}\right)+(1-\varphi)\left(P_{i, j}^{n}-P_{o_{i, j+1}}^{n}\right)\right]+\frac{1-\eta_{i}}{d z}\left[\rho \left(\bar{P}_{i, j}\right.\right. \\
& \left.\left.\quad-\bar{P}_{i, j+1}\right)+(1-\varphi)\left(P_{i, j}^{n}-P_{i, j+1}^{n}\right)\right]+D_{i, j+(1 / 2)},
\end{aligned}
$$

in which the index $n+1$ indicates the advanced-time value, while $\bar{P}$ is a hybrid pressure function formed from the equation of state. The weighting constant $\varphi$ varies from 0.0 to 1.0 , denoting the relative level of time centering of the pressure term, and $P_{o}$ is the pressure outside the containment.

In a similar fashion, a weighting constant $\theta$ varying from 0.0 to 1.0 can be used for the finite-difference mass equation to indicate relative level between purely explicit and purely implicit forms of the mass-conservation equation. That is,

$$
\begin{aligned}
\frac{\rho_{i, j}^{n+1}-\rho_{i, j}^{n}}{\delta t}= & \frac{\theta}{r_{i} \delta r}\left[r_{i-(1 / 2)}\langle\rho u\rangle_{i-(1 / 2), j}^{n+1}-r_{i+(1 / i)}\langle\rho u\rangle_{i+(1 / 2), j}^{n+1}\right] \\
& +\frac{1-\theta}{r_{i} \delta r}\left[r_{i-(1 / 2)}\langle\rho u\rangle_{i-(1 / 2), j}^{n}-r_{i+(1 / 2)}\langle\rho u\rangle_{i+(1 / 2), j}^{n}\right] \\
& +\frac{\theta}{d z}\left[\langle\rho v\rangle_{i, j-(1 / 2)}^{n+1}-\eta_{i}\left\langle\rho v_{0}\right\rangle_{i, j}^{n+1}+(1 / 2)-\left(1-\eta_{i}\right)\langle\rho v\rangle_{i, j+(1 / 2)}^{n+1}\right] \\
& +\frac{1-\theta}{d z}\left[\langle\rho v\rangle_{i, j-(1 / 2)}^{n}-\eta_{i}\left\langle\rho v_{0}\right\rangle_{i, j+(1 / 2)}^{n}-\left(1-\eta_{i}\langle p v\rangle_{i, j+(1 / 2)}^{n}\right]\right.
\end{aligned}
$$

The equation-of-state pressure function considered in this report is the same as that used by the ICE technique, ${ }^{3}$

$$
\bar{P}_{i, j}=P_{i, j}^{n}+c_{i, j}^{n}\left(\rho_{i, j}^{n+1}-\rho_{i, j}^{n}\right)
$$

in which $c_{i, j}^{n}=(\partial P / \partial \rho)_{i, j}^{n}$ is closely related to the speed of sound. 
With the elimination of $\rho_{i, j}^{n+1},\langle\rho u\rangle_{i \pm(1 / 2), j}^{n+1}$, and $\langle\rho v\rangle_{i, j \pm(1 / 2)}^{n+1}$ from Eqs. $13-$ 18 , the modified Poisson equation for the quasi-Eulerian cells, including the effects of the penetration hole, to be solved for $\bar{P}_{i, j}$ is

$$
\begin{aligned}
& \bar{P}_{i, j}\left[\frac{1}{c_{i, j}^{n}}+\theta \varphi \delta t^{2}\left(\frac{2}{\delta r^{2}}+\frac{2}{d z(d z+\delta z)}+\frac{1}{d z^{2}}=H_{i, j}\right.\right. \\
& +\theta \cos t^{2}\left[\frac{r_{i-(1 / 2)} \bar{P}_{i-1, j}+r_{i+(1 / 2)} \bar{P}_{i+1, j}}{r_{i} \delta r^{2}}+\frac{2 \bar{P}_{i, j-1}}{d z(d z+\delta z)}\right. \\
& \left.+\frac{\eta_{i} \overline{\mathrm{P}}_{o_{i, j+1}}+\left(1-\eta_{i}\right) \overline{\mathrm{P}}_{i, j+1}}{d z^{2}}\right]
\end{aligned}
$$

in which

$$
\begin{aligned}
H_{i, j}= & \frac{P_{i, j}}{c_{i, j}}+\frac{\theta \delta t^{2}}{r_{i} \delta r}\left[\frac{r_{i-(1 / 2)}(1-\varphi)}{\delta r}\left(P_{i-1, j}-P_{i, j}\right)\right. \\
& \left.-\frac{r_{i+(1 / 7)}(1-\varphi)}{\delta r}\left(P_{i, j}-P_{i+1, j}\right)+r_{i-(1 / 2)} A_{i-(1 / 2), j}-r_{i+(1 / 2)} B_{i+(1 / 2), j}\right] \\
& +\frac{\theta \delta t^{2}}{d z}\left[\frac{2(1-\varphi)}{d z+\delta z}\left(P_{i, j-1}-P_{i, j}\right)-\frac{\eta_{i}(1-\varphi)}{d z}\left(P_{i, j}-P_{o_{i, j+1}}\right)\right. \\
& \left.-\frac{\left(1-\eta_{i}\right)(1-\varphi)}{d z}\left(P_{i, j}-P_{i, j+1}\right)+C_{i, j-(1 / 2)}-D_{i, j+(1 / 2)}\right] \\
& +\frac{\delta t}{r_{i} \delta r}\left[r_{i-(1 / 2)}\langle\rho u\rangle_{i-(1 / 2), j}-r_{i+(1 / 2)}\langle\rho u\rangle_{i+(1 / 2), j}\right]+\frac{\delta t}{d z}\left[\langle\rho v\rangle_{i, j-(1 / 2)}\right) \\
& \left.-\eta_{i}\left\langle\rho v_{0}\right\rangle_{i, j+(1 / 2)}-\left(1-\eta_{j}\right)\langle\rho v\rangle_{i, j+(1 / 2)}\right] .
\end{aligned}
$$

As shown in Eq. 19, the boundary pressure above the quasi-Eulerian cell, $\overline{\mathrm{P}}_{i, j+1}$, is needed to solve the pressure in the quasi-Eulerian cell. During the iteration process, the velocity of the cover head can be obtained by the iterated pressure force exerted on the cover head. Based on this iterated cover-head velocity, $\bar{v}$, and the beginning-of-cycle velocity, $v^{n}$, the pressures above the quasi-Eulerian cells, $\bar{P}_{i, j+l}$, can be evaluated by the equation 


$$
\begin{aligned}
\frac{\left\langle\rho^{n} \bar{v}\right\rangle_{i, j}+(1 / 2)}{\delta t}-\langle\rho v\rangle_{i, j+(1 / 2)}^{n} & =\frac{1}{d z}\left[\varphi\left(\bar{P}_{i, j}-\bar{P}_{i, j+1}\right)\right. \\
& \left.+(1-\varphi)\left(P_{i, j}^{n}-P_{i, j+1}^{n}\right)\right]+D_{i, j+(1 / 2)^{\prime}}^{\prime}
\end{aligned}
$$

where $D_{i, j+(1 / 2)}^{\prime}$ has the same 1ormulation as $D_{i, j+(1 / 2)}$ in Eq. 12, except that $\eta_{i}$ is set equal to zero.

In summary, the procedure for a calculation cycle is as follows:

1. Calculate the required beginning-of-cycle terms, $R_{i+(1 / 2), j}$, $S_{i, j+(1 / 2)}, G_{i, j}$ for regular cells, and $A_{i-(1 / 2), j}, B_{i+(1 / 2), j}, C_{i, j-(1 / 2)}, D_{i, j+(1 / 2)}$, $D_{i, j+(1 / 2)}^{\prime}, H_{i, j}$ for quasi-Eulerian ceils.

2. Calculate $P_{i, j}$ for every cell, using the Poisson equation or the moving-boundary equation.

3. Calculate cover-head velocity, $\bar{v}$, using the iterated pressure force exerted on the cover head.

4. Calculate boundary pressures above the quasi-Eulerian cells, using Eq. 21 .

5. Repeat steps $2-4$ until the pressures in all the regular and quasiEulerian cells satisfy

$$
\bar{P}_{i, j}^{\ell+1}-\bar{P}_{i, j}^{\ell}<
$$

( $\varepsilon$ is a suitably chosen small number of order $10^{-4}$ ).

6. Solve for densities, $\rho_{i, j}^{n+1}$, using the equation of state.

7. Solve for velocities of all the cells, using the momentum equations.

8. Solve for velocities of the penetration holes, using Eq. 16.

9. Calculate the new values of the energy for every cell.

10. Calculate the new values of the sonic velocities for every cell.

11. Move the cover head to the new position. 


\section{INITIAL AND BOUNDARY CONDITIONS}

The present extended version of the ICE technique, including the quasiEulerian cells does not need pre-initial-time data. A subroutine SEllip generates the distribution of variable values throughout the mesh and represents the desired initial conditions of the fluid. The calculation carries on from there.

Many kinds of boundary conditions are possible. In cases such as rigid walls and inflow and outflow boundaries, the boundary conditions are specified by the behavior of the normal and tangential velocity components. At a free surface, the necessary conditions are that both the tangential and normal stresses must be vanished. For the boundary conditions above the moving grid, the boundary velocities are (see Fig. 4)

$$
u_{i+(1 / 2), j+!}=u_{i+(1 / 2), j} \text { and } u_{i-(1 / 2), j+1}=u_{i-(1 / 2), j} \text {. }
$$

in which $u_{i+(1 / 2), j}$ and $u_{i-(1 / 2), j}$ are the velocities in the irregular cells. As mentioned before, the boundary pressures above the moving mesh are determined by the momentum equation (Eq. 21).

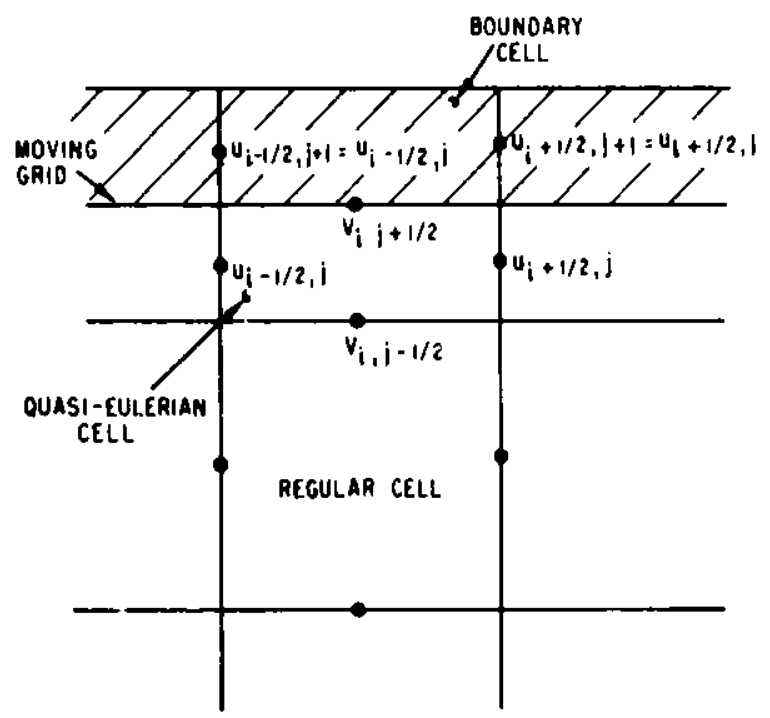

Fig. 1

Velocities in the Boundary (:cll above the Quasi-linterian cell

A thin-shell approach has been included in the ICECO code to treat the reactor wall as a moving boundary. The wall material can be considered to be elastic-plastic and strain-hardening. The fluid gives the reactor wall a uniform distributed load. In return, the reactor wall supplies the fluid a moving-boundary condition. In these moving-boundary cells, the fluid slips along the reactor wall in the tangential direction and moves together with the wall in the normal direction." 


\section{EXAMPLES}

A. Pressure Waves Generated by Slug Impact

The mathematical model of this example is shown in Fig. 5. A velocity of $2960 \mathrm{~cm} / \mathrm{s}$ is uniformly distributed in the axial direction. Two calculations

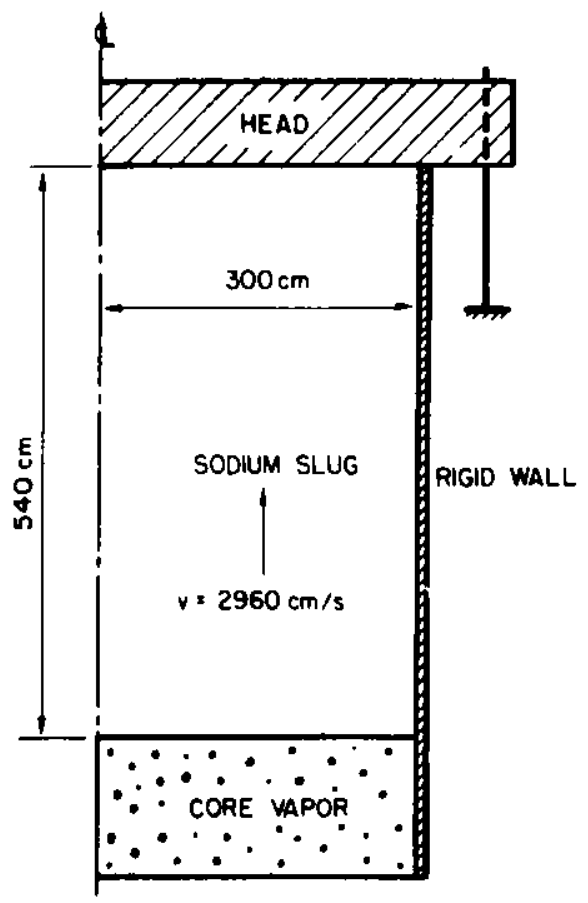

Fig. 5. Th:oretical Slug-impact Model were performed to compare the results obtained by the quasi-Eulerian method with the analytical predictions and the REXCO-code ${ }^{5}$ solutions.

The first one assumes the wall to be rigid. Thus, it is essentially a one-dimensional problem for which the analytical solution is well known. The reactor head is assumed to be stationary. Actually, this problem can be analyzed by a regular Eulerian mithod. However, for comparing results, the problem was analyzed using the newly developed quasi-Eulerian method, in which the axial size of each quasi-Eulerian cell is different from that of each regular cell, but it does not vary with time because of the stationary assumption.

In the analytical solution, the impact pressure exerted upon the stationary cover head is a function of the fluid density, the sonic velocity, and the particle velocity before the slug impact. With a fluid density of $0.8258 \mathrm{~g} / \mathrm{cm}^{3}$, a sonic velocity of $2.38 \mathrm{~km} / \mathrm{s}$, and a particle velocity of $2960 \mathrm{~cm} / \mathrm{s}$, the analytical impact pressure is 573 bars $(57.3 \mathrm{MPa})$. After impact, the pressure wave travels down through the coolant to the core region. As the pressure wave passes through the coolant, the velocity of the coolant behind the pressure wave is reduced to zero and the density of the coolant behind the pressure wave is increased. When the pressure wave reaches the interface of the coolant slug and the core vapor, a rarefaction wave is propagated back up to the coolant coilumn, successively, relieving the pressure. The analytical value of the time period required for traveling of the loading and unloading wave is $4.66 \mathrm{~ms}$

The calculated pressures in the upper center zone using the quasiEulerian method for a stationary head are shown in Fig. 6. A pressure of 571 bars ( $57.1 \mathrm{MPa}$ ) was generated under the cover head upon slug impact. The time period for the loading and unloading waves traveling $540 \mathrm{~cm}$ was found to be $4.6 \mathrm{~ms}$. The results obtained from the REXCO code are also shown by the dashed line in Fig. 6.

The second calculations are based on the assumption that the reactor wall is deformable. The radial deformation of the wall can relieve the pressure 
in the coolant slug. As the wall moves outward, a rarefaction wave travels radially inward, successively, relieving the pressure in the coolant slug. Figure 7 shows the solutions of the pressure in the upper center zone obtained by the quasi-Eulerian method, as compared to the REXCO-code predictions.

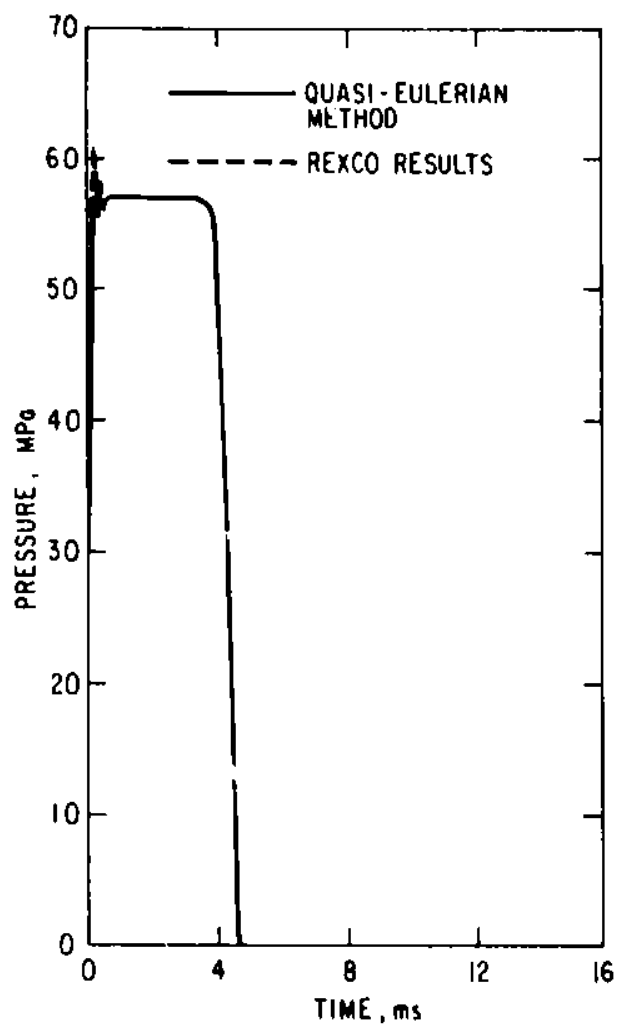

Fig. 6. Water-hammer Impulse for Theoretical Slug-impact Model

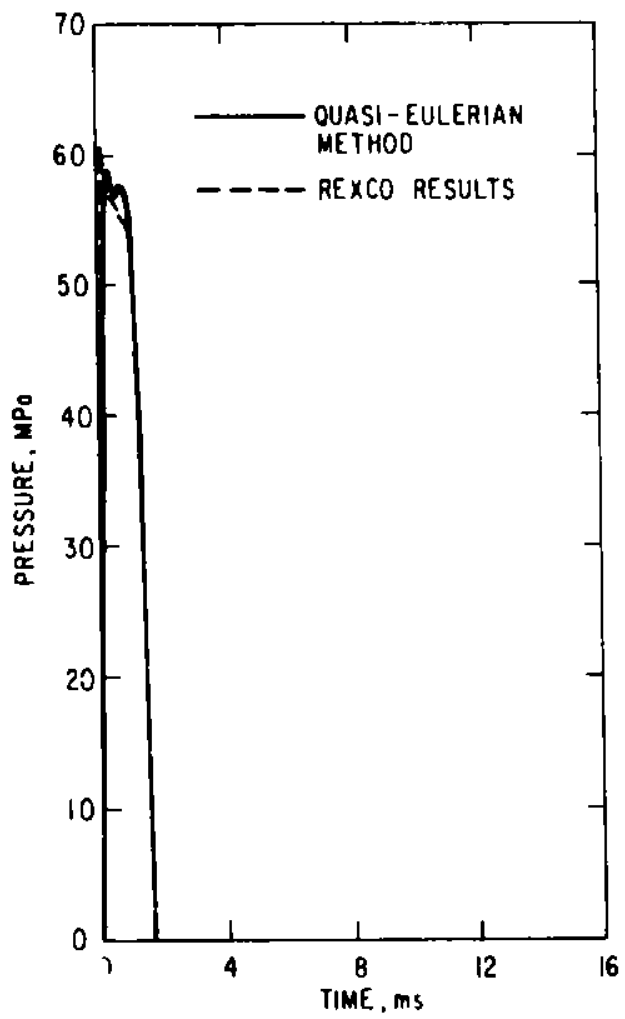

Fig. 7. Effect of Flexible Wall upon Pressure Unloading

The above comparisons have demonstrated that the quasi-Eulerian method can produce the same results as predicted by the analytical solution, as well as by the other codes.

B. Sodium Spillage through the Opening Gap at the Head-Wall Junction and the Penetration Hole

This study was perfurmed to investigate the eifects of the opening gap at the head-wall junction and the penetration holes on the slug-impact force. A. simplified reactor configuration for this study is shown in Fig. 8 . The elastic-plastic vessel wall was approximated by a bilinear stress-strain curve, as shown in Fig. 9. The initial pressure in the core region was as sumed to be 300 bars ( $30 \mathrm{MPa}$ ). Three calculations with the same initial reactor configurations have been performid for comparison. Case 1 assumed that there was a penetration hole on the top of the cover head and that a gap was generated at the head-wall junction upon slug impact. The wall deformation and coolant spillage at three instants--4.75, 8.5, and $18.5 \mathrm{~ms}$ after ine 
start of computation--are shown in Fig. 10, where the movement of the fluid particles and expansion of the core can also be seen.

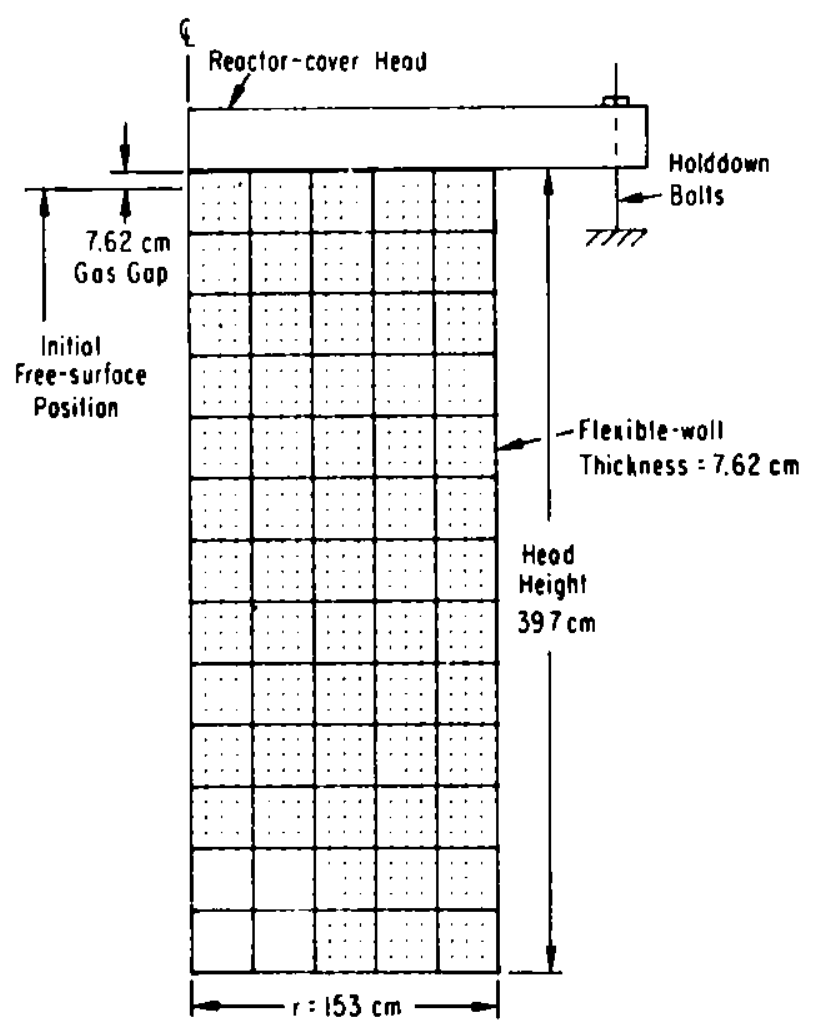

Fig. 8. Initia: Reactor Configuration for Example B. ANL Neg. No. 900-5249.

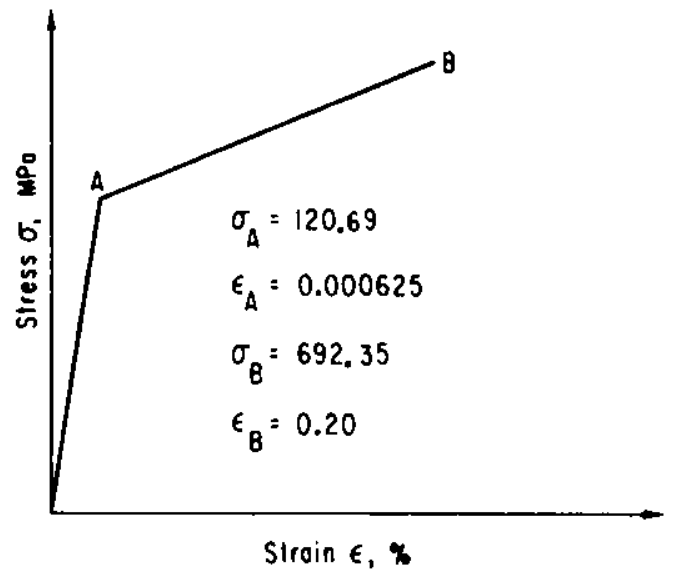

Fig. 9. Mechanical Properties of Vessel Wall

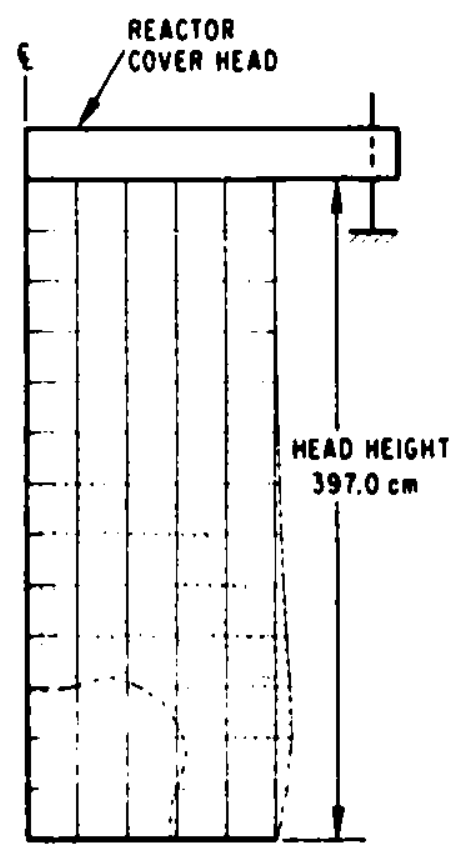

(0) TIME $=4.75 \mathrm{~ms}$

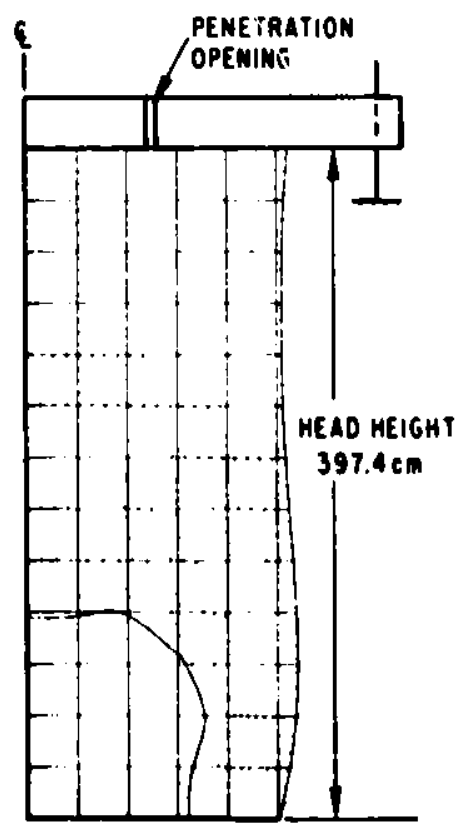

(0) TIME $=8.5 \mathrm{~ms}$

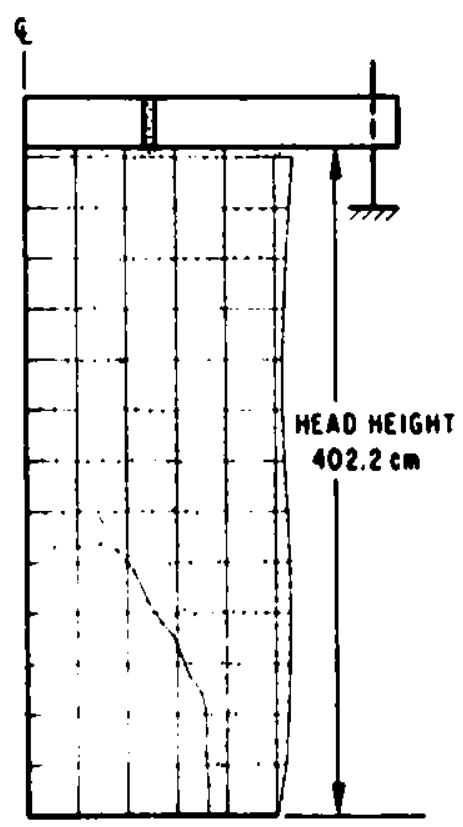

(c) TIME $=18.5 \mathrm{~ms}$

Fig. 10. Reactor Configurations at Varlous Tines 
Case 2 assumed that there was no penetration hole on the cover head, but that an opening gap was generated at the head-wall junction upon slug impact. Case 3 as sumed that there was no penetration hole, as well as no opening gap when the cover head moved upward. The forces on the cover hezd for these three cases are shown in Fig. 11. As expected, the plug force with the penetration hole and side spillage, as compared to the one without spillage and one with side spillage only, has been reduced.

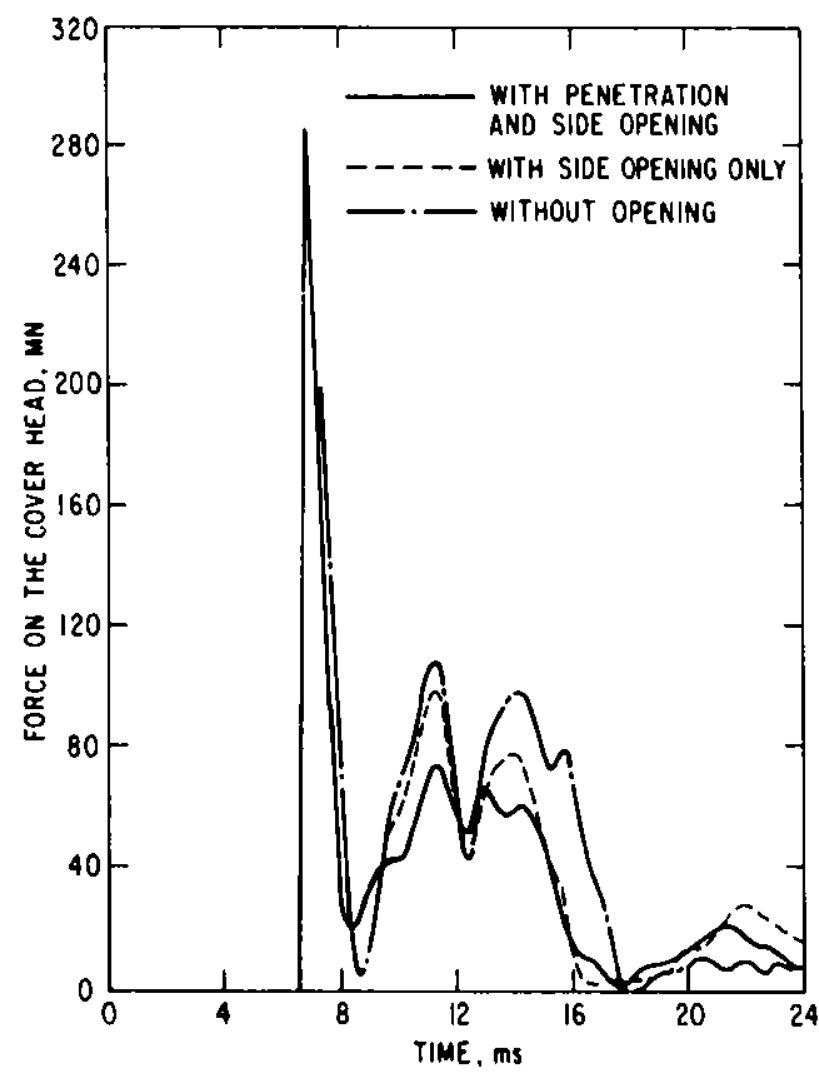

Fig. 11

Plug-force Histories

C. Comparison of the Results from the Quasi-Eulerian Method with the SL-1 Accident

On January 3, 1961, an accidental withdrawal of a control rod in the $\mathrm{SL}-1$ reactor resulted in a sudden release of $130 \mathrm{MW} \cdot \mathrm{s}$ nuclear energy. The instant heat release produced an abrupt coolant vaporization, driving the coolant mass upward, and producing a large impact force on the cover head and the upper-vessel wall. The velocity of the water slug just before impact was reported to be as high as $48.463 \mathrm{~m} / \mathrm{s}(159 \mathrm{ft} / \mathrm{s})$; the mass of the water slug driven upward was about $2918.78 \mathrm{~kg}$ (200 slugs). The estimated rise of the vessel upon slug impact was about $2.743 \mathrm{~m}(9 \mathrm{ft})$. Considerable damage was caused by the sudden release of energy and the subsequent slug impact. Detailed results of the accident are in the Final Report of the SL- 1 Recovery Operation, and the Additional Analysis of the SL-1 Excursion. ${ }^{6}$

Many attempts have been made during the past decade to estimate the amount of the energy release and to predict the vessel deformations, both 
analytically and experimentally. For example, Proctor ${ }^{7}$ has estimated the vessel damage using tise NOL containment explosion-response data; Argonne National Laboratory has performed calculations on the upper-vessel damage using the REXCO-H code. ${ }^{5}$ Although results of calculations on vessel de-

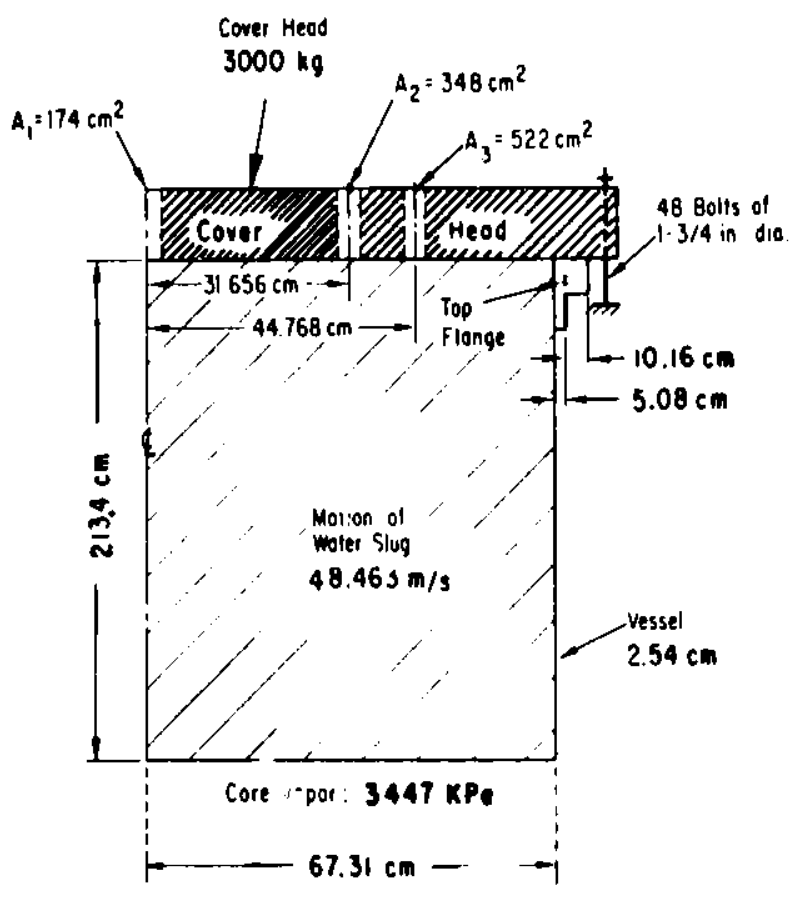

Fig. 12. Slug-Impact Model for Stal formation were in good agreement with the data from the SL- 1 accident, none of the calculations had taken into account the loss of coolant through the six holes on the cover head that were uncapped at the time of the slug impact. To establish the validity of the comparisons, the effect of the coolant spillage on slug impact must first be resolved.

With the introduction of the quasi-Eulerian method in the ICECO code, the SL-1 accident, including coolant spillage, can be more realis tically analyzed. The deformations in the upper-vessel region resulting frorn coolant slug impact are calculated with the extended ICECO code. The idealized model is shown in Fig. 12. The vessel data are based upon the original engineering drawing. The stress-strain

curve of the vessel material and the force-displacement curve of the cover bolts are approximated by the bilinear curves. The slug velocity and core pressure a the time of slug impact were $48.463 \mathrm{~m} / \mathrm{s}$ and $3447 \mathrm{kPa}$ (500 psi), respectively. (They are taken from the report of the SL- 1 Recovery Operation.) The six holes are represented by three annular spaces shown in Fig. 12 . The areas of the annular spaces used in the calculation are 174,348 , and $522 \mathrm{~cm}^{2}$, respectively.

Two calculations have been performed using the extended ICECO code: Case 1 assumes that there are six holes on the cover head and that water can also be expelled from the head and vessel juncture if a gap is generated there by the slug-impact force; Case 2 assumed no holes on the cover head as well as at the head-vessel juncture. The vessel deformations are shown in Fig. 13, where Case 1 is shown in a solid line. Case 2 in dotted lines, and the actual vessel deformation in dash-dot lines. The coolant spillage through the coverhead holes is seen to have a substantial effect on the wall deformation; it reduces the maximum wall deformation from 9.7 to $8.2 \%$, a reduction of $1.5 \%$. The difference of wall deformation at location A between the calculations using the quasi-Eulerian method and actual measurement is due to the fact that, in the real reactor, the deformation of the vessel wall was limited to $7.4 \%$ by the presence of the concrete containment wa!l. If, in the quasi-Eulerian-method 
calculations, the deformation of the vessel wall is also limited to $7.4 \%$, not only will the wall deformation at location A reduce, but also the wall deformation at location $B$ will increase, resulting in a better agreement with the actual vessel deformation.

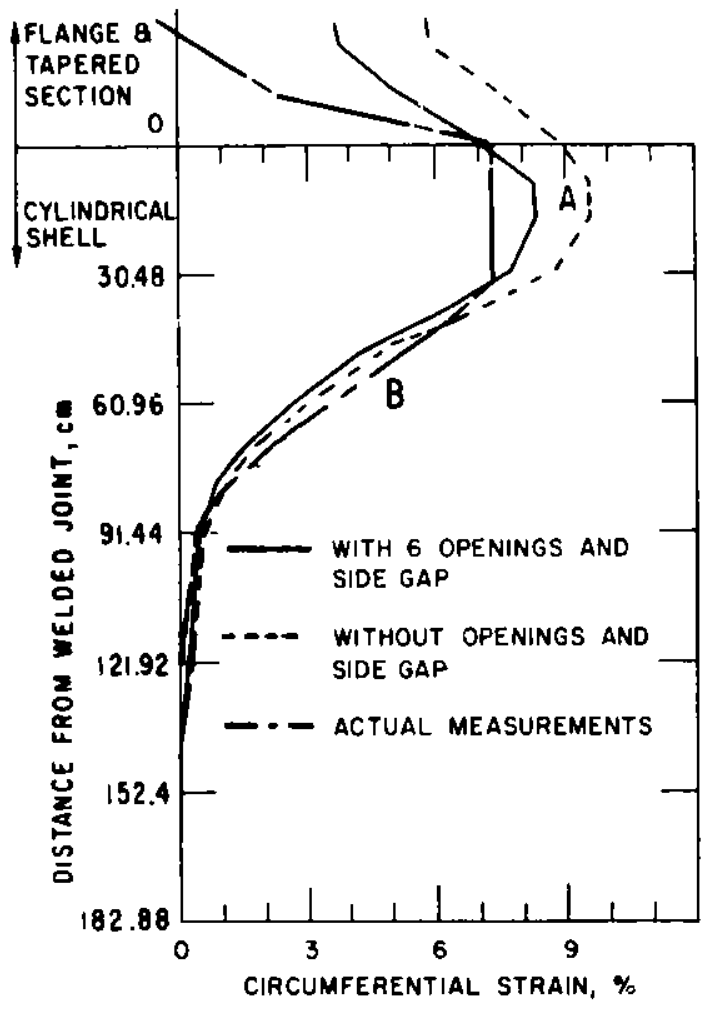

Fig. 13

Vessel Deformation of Deformed SI,-1 Profile 


\section{SUMMARY AND CONCLUSION}

This report has given a brief description and formulation of the quasiEulerian method. This method has been successfully incorporated into the ICECO code to study slug-impact and coolant-spillage froblems. To test the overall reliability of the code performance, the extended ICECO code, including the quasi-Eulerian cells, has been tested in a variety of circumstances. The results obtained by this quasi-Eulerian method are believed to be reasonable, especially when the axial size of the irregular cell is close to the axial size of the regular cell.

Three examples using the quasi-Eulerian method are given in this report. The first shows that the results, as indicated by the impact pressure and wave-traveling time period, are in close agreement with the analytical predictions and the REXCO-code solutions. The second example demonstrates the movement of the Marker particles expelled from the containment vessel, as well as the effects of the openings on the slug-impact force. The third example indicates that, without consideration of the openings, the deforration of the containment wall will be overestimated.

The slug-impact phenomena and the velocities at different openings depend on the responses of the entire reactor system. At present, the treatments of the core barrel, core supporting structures, etc., for the ICECO-code solutions using regular Eulerian cells are still under development. It is believed that, when all these treatments become available, the extended ICECO code can be readily used for analyzing the slug-impact and sodium-spillage problems in a typical reactor configuration consisting of various internal structures and a curved reactor vessel.

\section{ACKNOW LEDGMENTS}

I wish to thank Dr. Stanley H. Fistedis for his encouragement and advice, Dr. Y. W. Chang for his continued guidance and discussions, Dr. C. Y. Wang for his discussions and consultations on the ICECO code, Dr. A. H. Marchertas for his discussions on the thin-shell computer code, and Mr. J. Gvildys for his contribution of the CALCOMP-plot subroutine.

\section{REFERENCES}

1. A. H. Marchertas, Y. W. Chang, and S. H. Fistedis, Evaluation of Coolant Impact Effects on the Reactor Cover, ANL-7987 (Nov 1972).

2. C. Y. Wang, H. Y. Chu, Y. W. Chang, and S. 'I. Fistedis, "Application of the Implicit Eulerian Method (ICECO) to Fast Reactor Containment," Third Int. Conf. on Structural Mechanics in Reactor Technology, Vol. 2, Part E, Paper 3/4, London, UK (Sept 1-5, 1975). 
3. Francis H. Harlow and Anthony A. Amsden, A Numerical Fluid Dynamics Calculation Method for all Flow Speeds, J. Comput. Phys. 8, 197 (1971).

4. James A. Viecelli, A Computing Method for Incompressible Flows Bounded by Moving Walls, J. Comput. Phys. 8, 119 (1971).

5. Y. W. Chang, J. Gvildys, and S. H. Fistedis, Two-dimensional Hydrodynamics Analysis for Primary Containment, ANL-7498 (Nov 1969).

6. Final Report of SL-1 Recovery Operation, IDO-19311 (July 22, 1962); Additional Analysis of the SL-1 Excursion, IDO-19313 (Nov 21, 1962).

7. J. F. Proctor, Adequacy of Explosion-Response Data in Estimating ReactorVessel Damage, Nucl. Saf. 8, 565 (1967). 


\section{Internal:}

W. E. Massey

J. A. Kyger

L. Burris

D. W. Cissel

S. A. Davis

B. R. T. Frost

E. V. Krivanec

R. J. Teunis

C. E. Till

R. S. Zeno

H. O. Monson

R. Avery

J. F. Marchaterre

A. J. Goldman

H. K. Fauske

R. E. Henry

D. Rose

R. H. Sevy

I. Bornstein
W. C. Lipinski

J. B. Heineman

J. H. Tessier

D. R. Pedersen

C. E. Miller

D. H. Cho

C. E. Dickerman

F. E. Dunn

A. DeVolpi

M. Epstein

S. H. Fistedis

A. E. Klickman

J. M. Kramer

P. A. Lottes

R. A. Noland

A. B. Rothman

B. W. Spencer

D. P. Weber
H. U. Wider

J. E. Ash

Y. W. Chang

C. Fiala

J. Gvildys

J. M. Kennedy

R. F. Kulak

M. T. Abdel-Moneim

H. J. Petroski

H. Schreyer

C. Y. Wang

W. Zeuch

D. Myers

G. Ridges

H. Y. Chu (10)

A. B. Krisciunas ANL Contract File

ANL Libraries (5)

TIS Files (6)

\section{External:}

DOE-TIC, for distribution per UC.-79p (197)

Manager, Chicago Operations and Regional Office, DOE

Chief, Oflice of Patent Counsel, DOE-CORO

Director, Technology Management, DOE-CORO

Director, DOE-RRT (2)

President, Argonne Universities Association

Reactor Analysis and Safety Division Review Committee:

S. Brown, Burns and Roe, Inc.

I. R. Dietrich, Combustion En ineering, Inc.

W. Kerr, U. Michigan

M. Levenson, Electric Power Research Inst.

S. Levy, S. Levy, Inc.

D. Okrent, U. California, Los Angeles

N. C. Rasmussen, Massachusetts Inst. Technology 